\title{
A Psicologia racial no Brasil (1918-1929)
}

\author{
André Luís Masiero \\ Pontifícia Universidade Católica de Minas Gerais - Poços de Caldas
}

\begin{abstract}
Resumo
As teorias raciais chegaram ao Brasil por volta de 1869. Neste artigo procuramos demonstrar como estas teorias entraram no âmbito das ciências psicológicas e direcionaram conceitos e práticas. Foram analisados os anais da Sociedade Eugênica de São Paulo (1919) e os trabalhos apresentados no $1^{\circ}$ Congresso Brasileiro de Eugenia (1929), que tiveram como meta “melhorar a raça nacional”. Tanto aquela instituição quanto este evento científico contaram com a participação de psicólogos, psiquiatras e antropólogos que se aproximaram do racismo científico, muito difundido pelo mundo no início do século XX. Esta aproximação gerou uma “Psicologia Racial” no Brasil, a qual pretendia reduzir os saberes psicológicos a uma suposta problemática racial.
\end{abstract}

Palavras-chave: psicologia; raça; eugenia

\begin{abstract}
The race Psychology in Brazil (1918-1929). The arrival of racist theories in Brazil happened around 1869. The aim of this paper was to demonstrate how those theories got into the psychological sciences and conducted their concepts and practices. Documents from Sao Paulo Eugenic Society's archives (1919) and from the $1^{\text {st }}$ Brazilian Eugenics Conference (1929) have been analyzed, both proving to be committed with the “national race improvement”. Many psychologists, psychiatrists and anthropologists related to scientific racism - spread around the world in early $20^{\text {th }}$ century - took part of the institution as well as the conference. This fact brought about the "race psychology" in Brazil, which intended to reduce the psychological knowledge to a hypothetic racial problem.
\end{abstract}

Keywords: psychology; race; eugenics

$\mathrm{E}$ m um artigo publicado em 1955, Tristão de Ataíde, intelectual da Academia Brasileira de Letras, tido por seus contemporâneos como um "psicólogo de rara originalidade”, transcreveu um trecho do poeta grego Téognis de Megara, datado do século VI a.C., no qual parecia expor idéias raciais semelhantes às do século XIX:

Preocupamo-nos em ter burros e cavalos de boa raça porque sabemos que o bom procede do bom; entretanto um homem sadio não recusa desposar uma mulher doente se ela tiver dinheiro. É o dinheiro que abastarda a raça. Não há que admirar se esta decai, uma vez que o mal se cruza com o bom. (Ataíde, 1955, p. 77)

Como as teorias raciais disseminavam, a melhoria do gênero humano em todos os seus atributos fazia parte das aspirações naturais do homem. A favor deste argumento, os teóricos racistas sempre citavam textos de grandes filósofos, poetas e novelistas de todos os períodos da história intelectual. A que outro motivo se deveria o fato de serem encontradas idéias tão antigas sobre o desejo humano de "evoluir", isto é, de cuidar devidamente dos seus próprios atributos raciais, senão à sua própria natureza?
O estatístico, naturalista e psicólogo inglês Francis Galton (1822-1911) tentou reanimar esta idéia criando uma ciência a qual chamou de eugenia. Gabando-se de dar prosseguimento a uma história de passado tão remoto, seu livro Hereditary genius, de 1869, é considerado o fundador da ciência do "melhoramento racial humano".

Nesta obra, Galton definiria as diretrizes para o estudo e manipulação da hereditariedade com o objetivo de melhorar ao máximo as qualidades inatas das “raças humanas”, sobretudo suas habilidades mentais. Assim, justificava o fornecimento de maiores incentivos materiais para grupos que, embora numericamente pequenos, se destacassem em várias atividades, como artísticas, científicas ou econômicas. Galton queria assegurar que os indivíduos e grupos de melhor "qualidade racial” gerassem descendentes em maior quantidade.

Por outro lado, com o mesmo objetivo de "aprimorar a raça”, indivíduos acometidos por qualquer sinal de distúrbio mental ou físico deveriam abster-se da reprodução, mesmo que para isso o Estado se encarregasse compulsoriamente deste impedimento.

Às medidas incentivadoras dos "melhores" dotados biologicamente, Galton chamou de eugenia positiva e as 
impeditivas, dos "piores", chamou de eugenia negativa. Acreditava Galton que teria descoberto formas racionalmente sustentadas de intervir na evolução humana, feito que, embora há muito desejado pela humanidade, concretizava-se naquele momento com a sua obra. Subitamente, se auto-atribuiu a responsabilidade de guiar a humanidade para um mundo ideal, livre dos males que a assolavam, como o crime, a loucura, a doença, a feiúra etc., infortúnios individuais com perigosos reflexos coletivos. Quanto às diferenças entre as coletividades, Galton (1988) dizia que, segundo suas pesquisas, as raças humanas diferiam em capacidade intelectual, sendo a branca, a mais inteligente. Embora não se julgasse um pensador propriamente racista, até aquele momento nenhum argumento o convencia do contrário (Galton, 1988).

Estas teorias tiveram grande aceitação no mundo todo entre o final do século XIX e a primeira metade do século XX. Muitos foram os pensadores que defenderam a idéia das diferenças entre as raças, qualificando-as e hierarquizando-as das mais "evoluídas" para as mais "primitivas".

O Brasil foi muito citado entre os teóricos racistas e os darwinistas sociais europeus como um exemplo de degeneração produzida pela "miscigenação racial promíscua" (Stepan, 1990). Entre eles, o conde francês Joseph Arthur Gobineau, que esteve no Brasil entre abril de 1869 e maio de 1870 , como diplomata. Aqui, acreditava que teria encontrado a comprovação de que a miscigenação racial levaria à degeneração (Raeders, 1996).

Fechando-se o cerco, as teses racistas justificavam as estratégias eugênicas. Se a eugenia buscava as melhores condições de procriação, evidentemente condenava os enlaces entre indivíduos de "raças superiores" e "inferiores", ou entre representantes (indivíduos) raciais "inferiores", como doentes mentais, criminosos e alcoólatras.

Na interpretação racista, tínhamos, portanto, dois fatores básicos de "degradação humana": (1) a mistura de raças e culturas distantes e (2) a mistura entre indivíduos portadores de boas qualidades genéticas com aqueles já "degenerados" (principalmente portadores de deficiência física ou mental, tendências comportamentais desviantes, personalidades criminosas, prostitutas, alcoólatras), independentemente da etnia ou origem.

As propostas eugênicas procuravam atuar tendo estes dois pressupostos como bases irrevogáveis, que abarcavam tanto os problemas coletivos quanto os individuais.

No Brasil, estas idéias foram bem aceitas, tomando uma interpretação adaptada à realidade nacional.

Os saberes psicológicos ${ }^{1}$ tiveram intenso contato com as teorias raciais, pois estas forneciam subsídios para abordar problemas como as causas da loucura (Rocha, 1901), saúde mental (Cunha-Lopes, 1954), inteligência (Kehl, 1929), personalidade (Kehl, 1946), educação (Decroly, 1929) e do comportamento individual e social (Cavalcanti, 1933).

Nossa perspectiva histórica concentra-se justamente nos pontos de intersecção teórica entre os saberes psicológicos e o universo ideológico e científico circundante. Neste senti- do, podemos encontrar alguns termos e expressões que indicam esta relação entre eugenia e saberes psicológicos, por exemplo: "evolução psyquica da raça”" (Silva, 1931); "psycho eugenia” (Lopes 1938), "aperfeiçoamento mental” (Kehl, 1919), "psychologia do eugenico" (Vianna, 1930), "eugenico psychico” (Vianna, 1930), "psicologia étnica” (Vianna, 1991), "eugenia na profilaxia das moléstias mentais" (Pacheco e Silva, 1936), "melhoramento psíquico" (Pacheco e Silva, 1939), entre muitos outros. Estes termos refletem perfeitamente a apropriação e utilização dos pressupostos das teorias raciais pela medicina, antropologia, sociologia e psicologia. Por outro lado, refletem também uma certa psicologia dispersa pelas teorias raciais.

Segundo estes pressupostos, os chamados "inferiores" estariam mais sujeitos a anomalias hereditárias, como as desordens mentais. Logo, seria preciso determinar quem poderia legar suas características e quem, pela sua "inferioridade", não deveria passar às próximas gerações suas "tendências desviantes".

Neste trabalho focaremos nossa análise em dois momentos históricos: a criação da Sociedade Eugênica de São Paulo, em 1919, e a realização do Primeiro Congresso Brasileiro de Eugenia, em 1929. Este recorte é necessário devido a dois motivos. Primeiramente, estes eventos marcaram a tentativa da institucionalização das teorias raciais no Brasil via políticas públicas; para tanto, contaram com o apoio de cientistas voltados direta ou indiretamente a pesquisas em diversas áreas da psicologia e psiquiatria.

\section{"Melhoramento racial" e saberes psicológicos}

No Brasil, várias foram as tentativas de ações sociais que tinham a idéia da higiene racial como suporte, sobretudo no campo das ciências psicológicas.

Como veremos, vez por outra as teorias raciais e os saberes psicológicos encontraram em determinados momentos de suas histórias, ocasiões em que cooperaram entre si. Tivemos no país alguns eventos envolvendo a questão do "aprimoramento racial”: a Sociedade Eugênica de São Paulo, que funcionou entre 1918 e 1920; a realização do Primeiro Congresso Brasileiro de Eugenia, em 1929, no Rio de Janeiro; o Instituto Brasileiro de Eugenia ${ }^{2}$, no Rio de Janeiro, em 1929.

Tivemos ainda a realização de Concursos de Eugenia, entre 1929 e 1932, em São Paulo, quando se procurou selecionar os "exemplares raciais" brasileiros mais puros. Promovidos pelo Serviço Sanitário do Estado de São Paulo, dirigido em 1929 pelo Dr. Waldomiro de Oliveira, os concursos tinham o objetivo de selecionar matrizes para a constituição da futura "raça pura" nacional. Podiam se inscrever crianças de 3 a 5 anos de idade que passariam por análise genealógica e posteriormente avaliação física e mental (II Concurso de Eugenia, 1929).

Envolvendo boa parte da intelectualidade brasileira, estes eventos trataram direta ou indiretamente de problemas acerca da psicologia do brasileiro, abordando assuntos como o comportamento, a inteligência, a personalidade etc., tentando reduzir a psicologia à questão racial. 
Vejamos a seguir como estas instituições, que almejavam resguardar a "qualidade da raça nacional", trataram de questões psicológicas.

Conforme recomendações de Galton, a higiene racial deveria buscar subsídios em outras ciências, como na genética, teoria da evolução e mesmo na nascente psicologia. Os estatutos da Sociedade Eugênica de São Paulo (S.E.S.P.) previam estudos paralelos de outras ciências que poderiam subvencionar os argumentos eugênicos. Fundada em 14 de Janeiro de 1918, por iniciativa de Renato Ferraz Kehl e do Dr. Arnaldo Vieira de Carvalho, em sessão ordinária da Sociedade de Medicina e Cirurgia, realizada na Santa Casa de Misericórdia, a S.E.S.P. tinha como finalidades:

$\left.1^{\underline{0}}\right)$ O estudo e a applicação das questões da hereditariedade, descendencia e evolução para a conservação e aperfeiçoamento da especie humana;

$2^{\underline{0}}$ ) O estudo e applicação das questões relativas à influencia do meio, do estado economico, da legislação, dos costumes, do valor das gerações successivas e sobre as aptidões physicas, intellectuaes e moraes;

$\left.3^{\underline{0}}\right)$ O estudo das ciencias que se relacionam com a Eugenia;

$4^{\underline{0}}$ ) A divulgação entre o publico de conhecimentos hygienicos e eugenicos, para o bem do individuo, da collectividade e das gerações futuras;

$\left.5^{\underline{0}}\right)$ Concorrer para o exame pre-nupcial dos nubentes. (Sociedade Eugênica de São Paulo, 1919)

Temas psicológicos foram tratados já no discurso inaugural da sociedade, proferido pelo seu principal idealizador, Renato Ferraz Kehl. Para o eugenista brasileiro, a disciplina dos instintos humanos seria uma das primeiras condições para se alcançar, no futuro, uma raça nobre e equilibrada moral e fisicamente. Na sua perspectiva, seria necessário criarem-se mecanismos educativos dos impulsos naturais humanos, principalmente dos reprodutivos, a fim de mantê-los longe dos vieses degenerativos. Os instintos humanos, se atuassem desordenadamente, poderiam levar ao contato com doenças venéreas e alcoolismo, chamados também de venenos raciais.

Neste sentido, os eugenistas tinham um verdadeiro projeto normativo de regulação comportamental, a fim de incentivar o distanciamento da população dos males degenerativos.

Segundo Carrara (1996), para os higienistas do começo do século, as prostitutas, também chamadas de inimigas da família e da nação, eram responsabilizadas pela grande difusão da sífilis, cujos efeitos maléficos para a raça seriam semelhantes aos do álcool.

Por outro lado, a prostituição era tratada como um desvio comportamental próprio de raças com tendências à sexualidade desenfreada. No início do século XX, esta era uma das explicações para o fato de encontrarem-se tantas prostitutas negras nas grandes cidades brasileiras.

Para os eugenistas da S.E.S.P., a garantia de estimular na juventude os comportamentos adequados à saúde racial deveria passar necessariamente pela educação. Acima de tudo procurava-se uma forma de intervenção no indivíduo que pudesse moldar o seu eu de acordo com os sentimentos de responsabilidade para com a nação e a espécie humana. Não se tratava de uma educação apenas instrutiva, mas acima de tudo, formativa integral do caráter. Vários membros da Sociedade, ou que proferiram palestras nos encontros, compartilhavam desta idéia. O Dr. Rubião Meira (1919), professor de clínica médica da Faculdade de Medicina de São Paulo, defendia que o serviço militar obrigatório seria um meio ótimo de sanear a raça, pois poderia ter o papel de estimular os sentimentos patrióticos dos jovens. Ninguém gostaria de sentir-se um fardo para a nação ou para a espécie, tampouco prejudicá-la disseminando doenças.

Na mesma direção, Fernando Azevedo (1919), então primeiro secretário da S.E.S.P., enfatizava o esporte como fundamental para o desenvolvimento do caráter humano. Para tanto, servia-se de uma teoria de certa forma anacrônica, proveniente da reforma pedagógica inglesa durante a era vitoriana, segundo a qual o esporte estimularia as inervações cerebrais. Por este motivo, aqueles alunos mais bem formados e bonitos fisicamente, praticantes de esportes, teriam um desempenho acadêmico superior aos "fracos" e "feios". Segundo ele, isso poderia ser facilmente observado no cotidiano das escolas. Complementaria esta lapidação das virtudes físicas e psíquicas, a vida cotidiana regrada e longe das libertinagens advindas da urbanização. Para aqueles que penderiam para a devassidão, Fernando Azevedo (1919) utilizava uma classificação psicopatológica deveras inusitada: donjuanismo. Relembrando o mítico sedutor, esta psicopatologia comum nos homens jovens era caracterizada pela necessidade desenfreada de sedução e atividade sexual, o que atentava contra a moral e a saúde da raça.

Na S.E.S.P., em seu pouco tempo de funcionamento, predominou fundamentalmente o binômio higiene-eugenia. Numa vertente mais "ambientalista", a "pureza racial" a que se referiam os eugenistas da S.E.S.P. era a raça livre de anomalias contagiosas e degenerativas. Por isso, as ações eugênicas propostas nesta instituição quase sempre envolviam recomendações morais e comportamentais, pois, acima de tudo, propunham-se a afastar a população dos elementos degenerativos os quais, depois de adquiridos, poderiam degradar as próximas gerações.

Em outros momentos de sua obra, Kehl (1935) explicava como estes males afetariam a coletividade do ponto de vista de uma teoria biológica: poderiam ocorrer acidentes nas "células germinais" do homem ou da mulher, ocasionados pelo alcoolismo ou sífilis. Estas células, matrizes da constituição física, psicológica e moral da futura prole, uma vez danificadas, gerariam indivíduos defeituosos. Segundo esta visão, indivíduos expostos ao álcool ou sífilis teriam mais chances de ter filhos criminosos ou doentes mentais. Um alcoolista, por exemplo, caso se abstivesse do vício, até poderia recuperar seu potencial de gerar bons exemplares raciais, mesmo se no passado tivesse gerado filhos anormais. Cessados os agentes irritantes das células germinativas, estas voltariam ao normal. Mas todo o cuidado era pouco, alertavam os eugenistas, pois uma constante ação do álcool poderia gerar uma mutação 
definitiva nas células germinais, fixando a morbidade na herança familiar.

Além dessa teoria, o rigor científico biológico a que almejavam os eugenistas também era reforçado empiricamente com as observações clínicas realizadas em instituições de saúde mental. Um editorial do Boletim de Hygiene Mental (O álcool degenera, 1929) faz um relato de um caso desse tipo ocorrido em um hospital psiquiátrico brasileiro.

Durante a experiência profissional do autor ${ }^{3}$, este conheceu um casal muito próspero economicamente do interior do estado de São Paulo, que tinha dois filhos plenamente normais. Porém, por um motivo desconhecido, os negócios da família começaram a ruir: "Como se isto não bastasse, o seu chefe, incapaz de enfrentar com coragem a nova situação, inteiramente vencido pelo choque, tenta afogar seu desespero no álcool; inicia o vicio.” (O álcool degenera, 1929, p. 2). Durante este tempo o casal teve mais dois filhos.

Essas innocentes creaturas, que antes nunca deveriam ter visto a luz do dia (...) cresceram não podemos dizer, pois não mediam mais de $90 \mathrm{~cm}$ de altura. Eram pequenos monstros que quase não se pareciam com seres humanos (...). Si a parte physica era assim, peor ainda era a psychica. Na mais completa idiotia, privadas de qualquer das faculdades psychicas que caracterisam os seres humanos, tinham os cerebros inferiores ao de qualquer animal domestico. (...). A natureza, num gesto de piedade, não quis por certo, dar conciencia a esses infelizes, para que nunca podessem comprehender a propria hediondez. (O álcool degenera, 1929, p. 2)

Prosseguindo dramaticamente, o autor do editorial relata o profundo arrependimento e sentimento de culpa do pai diante da situação, concluindo que o álcool seria um fator altamente degenerativo da raça: “O pae comprehendendo tardiamente, mas ainda assim em tempo de evitar maiores males, abandonou o vício. Pois bem, depois disso vieram ao mundo outros filhos, tão normaes quanto os primeiros” (O álcool degenera, 1929, p. 3).

O álcool, portanto, teria sido o único motivo da degeneração dos dois filhos, pois após deixar o vício, os últimos nasceram e cresceram fortes e inteligentes. O "veneno racial" deixara de exercer seus malefícios, porém, a dívida com a sociedade e o estado já estava criada, pois estes "defeituosos" passariam toda a vida dependendo de caridade, do trabalho alheio e da assistência estatal.

Se os fatores ambientais, como o álcool, tinham uma grande influência na "qualidade racial”, não menos perigosos seriam os “inatos”. Com relação à transmissão de características psicológicas, conclui que “o grande factor plasmador das tendencias psychicas é a hereditariedade. O individuo já nasce com uma organisação psychica semelhante à dos seus ascendentes, como delles herda semelhanças físicas” (O álcool degenera, 1929, p. 3).

O texto, baseado no pressuposto da transmissão de características físicas e psicológicas, pela sua própria estética, pretende ser um alerta à sociedade em geral e especialmente aos alcoolistas, contumazes ou eventuais, não somente quan- to à sua própria saúde, mas também a algo que não lhes pertence: a saúde futura da "raça brasileira".

A crença na "superioridade racial” inata de alguns povos dominou parte da intelectualidade brasileira nos anos seguintes. É o que fica explícito nas idéias veiculadas nos eventos posteriores.

No Primeiro Congresso Brasileiro de Eugenia (1929), foram apresentados muitos trabalhos relacionando psicologia, raça e higiene. Realizado entre os dias 1 e 7 de Julho de 1929, na Faculdade de Medicina e no Instituto dos Advogados do Rio de Janeiro, foi o principal acontecimento das comemorações do centenário da Academia Brasileira de Medicina. Miguel Couto, em seu discurso de posse de presidência da Academia no ano anterior, havia feito a proposta de sua realização, manifestando uma preocupação com as ondas imigratórias que chegavam ao Brasil naquele período.

O Congresso, que foi presidido pelo antropólogo Edgard Roquette-Pinto, teve repercussão internacional e contou com a apresentação de mais de uma centena de trabalhos, posteriormente reunidos em três volumes. Sua estrutura foi muito parecida com a do Primeiro Congresso Mundial de Eugenia, realizado na Inglaterra, em 1912, que homenageou Galton no ano seguinte de sua morte. Visto a pretensão dos eugenistas de unificar as ciências sociais e biológicas em torno de seus ideais, buscavam as bases de seus argumentos em vários domínios. Os trabalhos apresentados abordaram temas bastante diversificados, como antropologia, educação, hereditariedade, genética, psicologia, legislação, imigração, estatística e consangüinidade.

Assim como todas as ações eugênicas, este congresso também organizou ações junto aos governos estaduais e federal e à população. Sintetizando os seus resultados, os participantes formularam dez resoluções finais que foram encaminhadas aos chefes de governo brasileiros. Várias dessas resoluções $-4^{\underline{a}}, 5^{\underline{a}}, 6^{\underline{a}}, 8^{\underline{a}}$ e $10^{\underline{a}}-$ envolveram importantes questões na interseção psicologia e raça:

Resumindo as finalidades praticas do trabalho que realizamos aqui submettemos as seguintes conclusões:

1ํㅜ) O Primeiro Congresso Brasileiro de Eugenia dirigirá ao Presidente da República, a casa do Congresso Nacional e aos governadores dos estados um appello em que serão postos em fóco os gravissimos perigos da immigração promiscua sob o ponto de vista dos interesses da raça e da segurança política e social da Republica;

$2^{\underline{0}}$ ) O Primeiro Congresso Brasileiro de Eugenia, considerando que as influencias mesologicas não podem alterar no individuo os característicos hereditarios transmittidos de geração em geração, julga que a selecção rigorosa dos elementos immigratorios é essencial e insubstituível como meio de defesa a nossa raça;

$3^{\underline{0}}$ ) O Primeiro Congresso Brasileiro de Eugenia aconselha que no processo de selecção de immigrantes sejam levados em conta os attributos collectivos da populações donde provieram as correntes immigratorias;

$4^{\underline{0}}$ ) O Primeiro Congresso Brasileiro de Eugenia, embora reconhecendo o valor da selecção por meio de uma escala differencial 
das correntes immigratorias em muito desejáveis, desejáveis e indesejáveis, julga entretanto, que o critério selectivo mais efficaz é do exame das condições individuaes de cada immigrante;

$\left.5^{\underline{0}}\right)$ O Primeiro Congresso Brasileiro de Eugenia chama a attenção dos poderes públicos para o facto de que a saúde physica do immigrante e a sua robustez muscular não bastam como característicos do valor eugênico do individuo, o qual só pode ser afferido pela apreciação das qualidades mentaes e moraes em que se traduzem os attributos profundos de sua herança, e, portanto, do seu valor como elemento racial; $6^{0}$ ) O Primeiro Congresso Brasileiro de Eugenia considera que os caracteristicos referidos na conclusão anterior, embora susceptíveis de apreciação por processos directos (tests), podem ser, entretanto, avaliados com sufficiente precisão por meios indirectos, isto é, por provas de habilitação profissional ou technica do immigrante, o seu contracto para serviços especializados por emprezas ou pessoas idôneas do paiz, ou pela posse de quantia substancial;

$7^{\underline{0}}$ ) O Primeiro Congresso Brasileiro de Eugenia, considerando que, entre as manifestações mais frequentes das taras hereditarias que incapacitam o immigrante como elemento ethnico indesejável, figuram formas de desequilíbrio mental traduzido em tendências anti-sociaes, aconselha a exclusão inflexível de todos os immigrantes com antecedentes criminaes;

$8^{\underline{0}}$ ) O Primeiro Congresso Brasileiro de Eugenia, considera que, nas condições actuaes dos paizes super populosos de alta civilização, os indivíduos que gravitam para o pauperismo attestam com esse proprio facto a sua inferioridade mental e moral, condemna todas as formas de immigração subvencionada, que apenas podem concorrer para a entrada no nosso paiz de elementos indesejaveis;

$9^{\underline{0}}$ ) O Primeiro Congresso Brasileiro de Eugenia aconselha de um modo geral uma política de reserva systematica em matéria immigratoria, lembrando aos poderes públicos da União e dos Estados que nas condições creadas pelo desenvolvimento mechanico de todas as formas de actividade productora, a questão numérica do povoamento passou a um plano secundário, dando-nos muito mais ampla liberdade de acção para exercermos desassombradamente severa vigilância na selecção de immigrantes;

$10^{\circ}$ ) O Primeiro Congresso Brasileiro de Eugenia aconselha a exclusão de todas as correntes immigratorias que não sejam da raça branca. (Primeiro Congresso Brasileiro de Eugenia, 1929, p. 339-340)

Esta seqüência mostra explicitamente quais eram os indivíduos e grupos “indesejáveis”. De maneira geral, os trabalhos apresentados no congresso não admitiam a transmissão de características adquiridas. Para os eugenistas isto representou um avanço no sentido de abandonar os pressupostos lamarckistas, o que há muito tempo já vinha sendo questionado no mundo todo, até mesmo por Galton. Um meio ambiente saudável poderia melhorar as condições de vida coletiva, no entanto, jamais modificar os atributos genéticos indeléveis de alguns indivíduos e grupos raciais. É o que mostram a $8^{\underline{a}}$ e a $10^{\underline{a}}$ resoluções. Mesmo em países altamente desenvolvidos - entenda-se um ambiente favorável ao desenvolvimento mental normal - havia indigentes, o que atestava sua "inferioridade biológica”.

Particularmente a raça negra não atingiria o mesmo patamar de desenvolvimento dos brancos devido à sua condição definitivamente inferior. Desaconselhavam assim a imigração deste povo ao país.

Segundo o antropólogo Oliveira Vianna (1959, p. 196), pesquisas comparativas das capacidades intelectuais de brancos e negros realizadas na Europa encontraram os seguintes resultados: a porcentagem de superdotados entre os brancos seria por volta de $5 \%$ desta população, já a porcentagem de negros de inteligência superior não passaria de $0,8 \%$.

Isto implica uma questão psicológico-racial fundamental. Mais próxima da eugenia galtoniana, a qual admitia a melhoria racial apenas através dos cruzamentos entre elementos a priori de boa constituição física e mental, o congresso convoca as ciências psicológicas para efetivar a seleção dos imigrantes desejáveis, através de técnicas diretas, com os próprios testes mentais, ou meios indiretos, observando as aptidões profissionais, requisito básico para quem vinha em busca de trabalho e melhores condições de vida. A prévia formação profissional do imigrante constituía uma prova favorável à sua normalidade moral, pois isto o afastaria dos males sociais como a prostituição e o alcoolismo, sem contar que seria também uma prova de sua boa “constituição racial”. Alguns trabalhos apresentados abordavam temas como ociosidade e vagabundagem como sérios problemas de comportamento passíveis de medicação psiquiátrica (e.g., Carvalho, 1929). Portanto, de nada adiantariam as ações mesológico-higiênicas, ou uma normatização comportamental segundo preceitos morais rígidos, como tinham tentado os eugenistas da S.E.S.P., se a população do país não fosse em si de "boa qualidade". Assim, caberia à psicologia um papel fundamental na formação do estado nacional coeso. As então novas técnicas de exame psicológico possibilitariam a seleção da população desejável para o país, segundo as peculiaridades naturais dos povos que aqui aportavam. A $5^{\underline{a}}$ e a $6^{\underline{a}}$ resolução do congresso refletem com precisão este ponto de vista.

No mais, o imigrante deveria mostrar sua viabilidade econômica para o país, tanto pela sua capacidade para o trabalho honesto, o que era demonstrado por meio dos testes psicológicos e observações diretas, quanto pela posse de quantia substancial para investimentos no país. A máxima eugênico-econômica era "oferecer mais ao país do que dele subtrair".

O trabalho apresentado por Ubirajara da Rocha e Arauld Bretas (1929), médicos assistentes do Laboratório de Psychologia da Fundação Gaffrée Guinle do Engenho de Dentro, no Rio de Janeiro, trouxe uma revisão das técnicas de seleção de pessoal para a indústria de acordo com a teoria do discriminacionismo affectivo, proposta por Waclaw Radecki. Claramente influenciado pelas idéias de Galton, a técnica do psicólogo polonês radicado no Brasil, 
buscava uma caracterização do perfil psicológico através de uma correlação psico-fisiológica individual. Seu teste classificava quantitativamente as faculdades do Inttelecto (visão, audição, sensações estáticas e kinestesicas, faticabilidade, tempos de reação, processos imaginativos, atenção, memória e pensamento), da Affectividade (sensibilidade e emotividade) e da Vontade (habilidade, aptidões e persistência). Com este teste traçavam-se perfis individuais, segundo a acuidade sensitiva e a caracterização volitiva e afetiva, exatamente como recomendavam as resoluções do congresso.

Outros trabalhos parecem ter contribuído significativamente para formação destas resoluções, mostrando que a quantidade de maus elementos raciais no país deveria ser motivo de grande atenção estatal e científica, se realmente se desejasse construir uma nação civilizada. Com inflexões alarmistas, vários participantes apresentaram pesquisas sobre a quantidade de elementos "indesejáveis" dispersos pelo território, objetivando sumariar o estado eugênico da raça brasileira.

A convite de Miguel Couto, Bulhões de Carvalho levou ao congresso a Estatística dos tarados do Brazil (Carvalho, 1929). Embora atualmente o indecoroso termo tarado sirva exclusivamente para designar pendores sexuais criminosos, em 1929, englobava um enorme rol de deficiências. Somente deste trabalho, compilamos alguns sinônimos de tarado usados freqüentemente para fins classificatórios: Débeis mentais, atrasados, cegos, surdos-mudos, epilépticos, toxicômanos, alienados mentais, vagabundos, dementes, cretinos, idiotas, imbecis, defeituosos e aleijados.

A contagem dos "tarados do Brasil" foi realizada pela primeira vez no censo de 1872 e teve como principal função prever o impacto econômico que esta população causaria ao país, devido não poderem arcar com o próprio sustento. Deste ponto de vista todos eram classificados como incapazes irremediáveis, por isso mesmo, onerosos ao estado e à parcela sã da sociedade.

Entre os tarados, o doente mental era a categoria mais difícil de ser recenseada, pois disseminados pelas cidades e pelas famílias passariam despercebidos, ao contrário dos surdos-mudos e aleijados, que eram mais facilmente reconhecidos. Bulhões de Carvalho, baseado na literatura estrangeira, admitia que por causa disso não se poderia saber com precisão a quantidade de doentes mentais no Brasil. O ideal seria contar a população internada nos hospitais psiquiátricos, desde que todos os doentes mentais dispersos fossem realmente internados, defendia o estatístico brasileiro. Quanto mais preciso o número, maior facilidade na previsão dos gastos que o país teria para sustentá-los. Eis então novas funções para a instituição psiquiátrica: facilitar a quantificação, impedir a reprodução dos internados e prever o prejuízo econômico que causariam à sociedade.

Como muitos outros autores mostraram, estes grandes gastos com a assistência justificariam as ações eugêniconegativas, pois com a diminuição do número de doentes mentais, caríssimos aos cofres da nação, maiores investimentos poderiam ser destinados à população "normal e produtiva", uma concepção administrativa evidentemente voltada ao "melhoramento racial".

\section{A atualidade da polêmica}

Embora com uma retórica ligeiramente diferente, segundo Moysés e Collares (1997), ainda hoje há reflexos destas idéias nos instrumentos seletivos utilizados pela psicologia. Muitos outros autores também apontam para a atualidade da questão. Pereira (1996), por exemplo, nos alerta para um certo "racismo", o qual, na verdade, nunca foi completamente sepultado pela sociedade moderna e que atualmente emerge sob diversas formas de etnocentrismo.

Em pesquisas já concluídas (Masiero, 2002), pudemos verificar que parte dos instrumentos utilizados pela psiquiatria no começo do século, com objetivos eugênicos e de controle social, guardam afinidades com algumas técnicas utilizadas atualmente, ainda que com propósitos ligeiramente diferentes, principalmente as medidas psicológicas de inteligência, os psicodiagnósticos e as técnicas de avaliação da personalidade. Sem contar as idéias presentes em nossa cultura sobre as características psicológicas, muitas vezes infamantes e estigmatizadoras da composição cultural brasileira: os sírio-libaneses são avaros, os mestiços preguiçosos, os orientais retraídos, mas inteligentes; imagens que parecem transportadas integralmente da ciência do século XIX, para este início de século. De acordo com Paty (1998), "as realidades sociais, os comportamentos e as mentalidades sempre demoram a se transformar. E a erradicação definitiva do pensamento desigualitário, pode-se imaginar, seria uma obra de grande fôlego" (p. 157).

As demonstrações atuais de intolerância contra minorias étnicas, religiosas e sexuais, comuns no mundo todo, Brasil incluído, nos indicam que não se trata de um assunto definitivamente encerrado, circunscrito a um passado longínquo e esquecido, como pode parecer à primeira vista; mas de um grave problema contemporâneo, cabendo, portanto, contestar o papel da ciência, sobretudo da psicologia, na construção histórica de preconceitos raciais e estigmas diversos.

Não só no meio social, mas também no científico, temos verificado uma ameaça de retorno das teses racistas. Richard Lynn, psicólogo da Ulster University, na Irlanda do Norte, vem tentando demonstrar que há diferenças significativas de inteligência entre as "raças humanas", corroborando estudos de Cyril Burt, Arthur Jensen e Hans Eysenck (Lynn, 1991). Seus argumentos apóiam-se em três pilares do racismo científico já bem conhecidos dos historiadores da psicologia. Primeiramente as notas de QI das "raças humanas". Os “mongóis” teriam um QI médio de 100-106; os caucasóides de 100; e os negros não passariam de 70 (Lynn 1991). A segunda evidência viria das medidas dos tempos de reação. Igualmente, os negros teriam reflexos mais lentos. A terceira evidência, segundo Lynn, seriam as culturais, sendo as raças brancas mais adiantadas e civilizadas que as negras.

Lynn é um dos editores do Mankind Quaterly. Ainda corrente, trata-se de um periódico especializado em raça, 
hereditariedade, etno-psicologia, história racial e genética humana.

Estes resultados, que insistem em se impor como científicos, em nada permitem alegar qualquer forma de hierarquia humana. Antes de tudo, devemos atentar para o fato de que a testagem mental nasceu já com a intencionalidade de mostrar que os povos e os indivíduos se diferenciavam em capacidade mental, assim, não poderiam mesmo encontrar outro resultado. Mesmo que os testes de inteligência meçam alguma capacidade mental, o que é duvidoso, o que fazem é medir estados mentais e não traços. O estado em que se encontra um indivíduo no momento da testagem é que determinará o resultado; portanto, podem mudar em curto prazo. Isto não permite qualquer forma de hierarquização. Os estudos de Lynn, Ciryl Burt e Hans Eysenck apresentam os resultados como se fossem traços psicológicos de uma população ou indivíduo, isto é, atribuem uma quantidade de inteligência imutável, independentemente do momento histórico ou social em que vive o sujeito coletivo ou individual estudado.

No Brasil, as interpretações racistas no âmbito das ciências psicológicas encontraram uma resistência a partir dos anos 50, sobretudo pela crítica que Gilberto Freyre empreendeu contra a "hierarquia racial”. Em Casa grande e senzala, há um capítulo no qual o antropólogo brasileiro faz uma revisão crítica dos resultados dos testes de QI como forma de estabelecer uma ordem decrescente de inteligência dos povos. (Freyre, 1963, p. 332-337). Influenciado por Franz Boas, Freyre mostra como os fatores ambientais até aquele momento haviam sido menosprezados, sendo um dos pioneiros no mundo a perceber a pertinência desta crítica. Basta lembrar que no mesmo período estavam em ascensão os estudos Cyril Burt, os quais pouco tempo depois vieram a se revelar inexatos, pesando sobre o psicometrista inglês suspeitas de fraude científica. (Eysenck versus Kamin, 1982).

Atualmente não há no Brasil estudiosos empenhados em tentar comprovar diferenças raciais de qualidades mentais, tampouco trabalhos com as mesmas tendências de Burt ou Lynn. Apesar destas publicações, linhas de pesquisa no campo da própria psicometria, no Brasil e no mundo, vêm fazendo uma forte crítica da supervalorização da determinação genética da inteligência (Roazzi, 1994; 2002).

Neste ponto, a História da Psicologia assume um papel fundamental na formação crítica do profissional ou pesquisador ao desvelar como a ciência, ao longo do tempo, modifica seus paradigmas básicos e aplicações. Para além de sua suposta neutralidade, no passado ou no presente, a ciência pode servir a interesses de classes ou de justificativas para a segregação de minorias, sobretudo no Brasil, onde as teorias racistas foram outrora cultivadas por uma elite intelectual motivada mais ideológica que cientificamente.

\section{Agradecimentos}

$\mathrm{O}$ autor agradece à FAPESP pelo apoio recebido (Processo $\left.\mathrm{N}^{\mathrm{o}} 00 / 06875-9\right)$.

\section{Referências}

O II Concurso de Eugenia [Editorial] (1929). Boletim de Eugenia, 1(12), 6.

O álcool degenera ou não a prole? [Editorial] (1929). Boletim de Hygiene Mental, 8, 2-3.

Ataíde, T. (1955). O eugenismo é aceitável? In J. de Lacretelle \& T. de Ataíde (Orgs.), O problema sexual ( $5^{\mathrm{a}}$ ed.). Porto: Tavares Martins.

Azevedo, F. (1919). O segredo de Marathona. In Sociedade Eugênica de São Paulo (Org.), Annaes de eugenia (pp. 113-135). São Paulo: Revista do Brasil.

Bizzo, N. M. V. (1994/95). O paradoxo social-eugênico, genes e ética. Revista USP, 24, 28-37.

Carneiro, L. (1929). A esterilização eugênica dos degenerados. Revista de Criminologia e Medicina Legal, 14, Julho-Dezembro, 14-28.

Carrara, S. (1996). Tributo a Vênus: a luta contra a sífilis no Brasil, da passagem do século aos anos 40. Rio de Janeiro: Fiocruz.

Carvalho, B. (1929). Estatística dos tarados do Brazil. In Anais do $1^{\circ}$ Congresso Brasileiro de Eugenia (pp. 225- 263), Rio de Janeiro.

Cavalcanti, P. (1933). Investigações sobre as religiões do Recife: uma seita panteísta. Arquivos da Assistência a Psicopatas de Pernambuco, 3, 58-68.

Cunha-Lopes, I. (1954). Higiene mental: sinopse de psiquiatria à luz dos modernos conhecimentos de genética, eugenia, psicopatologia, profilaxia, psicohigiene e pedagogia. Rio de Janeiro: Irmãos Pongetti.

Decroly, O. (1929). A selecção dos bem-dotados. Boletim de Eugenia, 18, 1-2.

Eysenck, Hans versus, Kamin, Leon (1982). O grande debate sobre a inteligência. Brasília: Editora da UnB.

Freyre, G. (1963). Casa-Grande e senzala: a formação da família brasileira sob o regime da economia patriarcal, Rio de Janeiro: Editora UnB.

Galton, F. (1988). Natural abilities and the comparative worth of races. In L. T. Beenjamin Jr. (Org.), A history of psychology. Original sources and contemporary research. Nova York: McGraw Hill.

Kehl, R. F. (1919). O que é eugenia. In Sociedade Eugênica de São Paulo (Org.) Annaes de eugenia (pp. 219-223). São Paulo: Revista do Brasil.

Kehl, R. F. (1929). Hereditariedade e intelligencia. Boletim de Eugenia, 6, 8.

Kehl, R. F. (1946). Tipos vulgares: introdução à psicologia da personalidade. Rio de Janeiro: Francisco Alves.

Lopes, E. (1938). Eugenia e hygiene mental [conferência na Sociedade de Medicina e Cirurgia de São Paulo - Sessão 10/outubro/1938]. Annaes Paulistas de Medicina e Cirurgia, 6, 621-622.

Lynn, R. (1991). Race differences in intelligence: a global perspective. The Mankind Quaterly, 31(3), 255-296.

Masiero, A. L. (2002). Psicologia das raças e religiosidade no Brasil: uma intersecção histórica. Psicologia: Ciência e Profissão, 22(1), 66-79.

Massimi, M. (1990). História da psicologia brasileira: da época colonial até 1934. São Paulo: EPU.

Meira, R. (1919). Factores de degeneração de nossa raça. In Sociedade Eugênica de São Paulo (Org.), Annaes de eugenia (pp. 45-64). São Paulo: Revista do Brasil.

Moysés, M. A. A., \& Collares, C. A. L. (1997). Inteligência abstraída, crianças silenciadas: as avaliações de inteligência. Psicologia USP, 8, 63-89.

Mosca, G. (1975). A doutrina do Super-Homem e as teorias racistas. In História das doutrinas políticas (pp.289-305). Rio de Janeiro: Zahar.

Pacheco e Silva, A. C. (1936). Problemas de higiene mental. São Paulo: Oficinas Gráficas do Hospital Juquery.

Pacheco e Silva, A. C. (1939). Psiquiatria clínica e forense. São Paulo: Vademecom.

Paty, M. (1998). Os discursos sobre as raças e a ciência. Estudos Avançados, 33, $157-170$.

Pereira, J. B. B. (1996). O retorno do racismo. In L. M. Schwarcz \& R. S. Queiroz (Orgs.), Raça e diversidade. São Paulo: EDUSP. 
Primeiro Congresso Brasileiro de Eugenia [Anais] (1929). Resoluções (Vol. I). Rio de Janeiro: Autor.

Raeders, G. (1996). O conde de Gobineau no Brasil. Rio de Janeiro: Paz e Terra. Ribas, J. C. (1945). Imigração e higiene mental. Boletim de Higiene Mental, 7, Março, 1-4.

Roazzi, A. (1994). A influência da motivação em tarefas cognitivas: nível sócio econômico, tipo de recompensa e contexto da tarefa. Psicologia: Teoria e Pesquisa, 2(10), 231-248.

Roazzi, A. (2002). Repensando a inteligência. Paidéia, 23(12), 31-56.

Rocha, F. (1901). Causas da loucura. Revista Médica de São Paulo, 5.

Rocha, U., \& Bretas, A. (1929). Contribuição ao estudo dos psychogrammas. In Anais do $1^{\circ}$ Congresso Brasileiro de Eugenia (pp. 205-223), Rio de Janeiro.
Silva, L. L. (1931). Cruzamento do preto com branco. Boletim de Eugenia, 30(3), 3-4.

Sociedade Eugênica de São Paulo (Org.). (1919). Annaes de eugenia. São Paulo: Revista do Brasil.

Stepan, N. L. (1990). Eugenics in Brazil. 1917-1940. In M. B. Adams (Org.), The wellborn science, eugenics in Germany, France, Brazil and Russia. Oxford: Oxford University Press.

Vianna, F. J. O. (1930). Os typos eugenicos. Boletim de Eugenia, 19, 3-4.

Vianna, F. J. O. (1932). Raça e assimilação. Rio de Janeiro: José Olympio.

Vianna, F. J. O. (1991). O eugenismo paulista. In Ensaios inéditos (pp. 69-73). Campinas: Editora da UNICAMP. (publicado no jornal Correio Paulistano, em 1927)

1 No período estudado a psicologia estava se estruturando como ciência, porém, não havia o psicólogo, como cientista ou profissional independente. A psicologia, por ser uma ciência nova, era produzida por médicos, educadores, filósofos entre outros. Estamos denominando saberes psicológicos essa psicologia dispersa por vários campos de saber anterior a sua autonomia (Massimi, 1990).

2 Posteriormente passou a ser chamado de Comissão Central Brasileira de Eugenia.

3 O autor não é identificado.

André Luís Masiero, doutor em Psicologia pela Universidade de São Paulo, Campus de Ribeirão Preto, é professor adjunto no Departamento de Psicologia da Pontifícia Universidade Católica de Minas Gerais, Campus de Poços de Caldas. Endereço para correspondência: Rua 28 de Setembro, 2365; Centro; São Carlos, SP; CEP 13560-270. Tel.: (16) 3307-5227.E-mail: masiero@yahoo.com 